\title{
PERBANDINGAN METODE TSUKAMOTO, METODE MAMDANI DAN METODE SUGENO UNTUK MENENTUKAN PRODUKSI DUPA (Studi Kasus : CV. Dewi Bulan)
}

\author{
Komang Wahyudi Suardika ${ }^{1 \S}$, G.K. Gandhiadi ${ }^{2}$, Luh Putu Ida Harini ${ }^{3}$ \\ ${ }^{1}$ Program studi Matematika, Fakultas MIPA - Universitas Udayana [Email: dockmathws92@gmail.com] \\ ${ }^{2}$ Program studi Matematika, Fakultas MIPA - Universitas Udayana [Email: gandhiadigk@yahoo.com] \\ ${ }^{3}$ Program studi Matematika, Fakultas MIPA - Universitas Udayana [Email: ballidah@gmail.com] \\ ${ }^{\S}$ Corresponding Author
}

\begin{abstract}
This research aims at knowing the comparison among Tsukamoto method, Mamdani method, and Sugeno method in deciding the production of incense at CV. Dewi Bulan. The research discussed about Tsukamoto method, Mamdani method and Sugeno method which consisted of four step, they are: fuzzyfication, forming a fuzzy rules, fuzzy logic analysis, and defuzzyfication. In conclusion, Sugeno method was found to be the best to be used in deciding the number of incense sticks production, comparing with the others. Sugeno method has probability of error value about 1,314\%.
\end{abstract}

Keywords: Fuzzy logic, Tsukamoto method, Mamdani method, Sugeno method, fuzzyfication, fuzzy logic, defuzzyfication.

\section{PENDAHULUAN}

Seiring perkembangan teknologi, telah berkembang berbagai macam cara untuk memproduksi suatu produk. Jumlah produksi suatu produk dipengaruhi oleh berbagai macam faktor, diantarnya; faktor harga, jumlah pekerja, transportasi, alat produksi, jumlah permintaan, jumlah persediaan dan faktor lainnya yang dibutuhkan oleh perusahaan untuk memproduksi produk tersebut. Untuk menentukan jumlah produksi suatu produk terdapat berbagai macam cara yang dapat digunakan, salah satunya adalah dengan menggunakan metode pada logika fuzzy (Susilo, 2006).

Metode inferensi logika fuzzy secara umum dapat digunakan untuk menentukan jumlah produksi suatu produk, terdapat tiga metode yang dapat digunakan yaitu; metode Tsukamoto, metode Mamdani dan metode Sugeno (Setiadji, 2009: 195). Pada prosesnya metode Tsukamoto dibagi menjadi empat tahap yaitu fuzzifikasi, pembentukan aturan, analisis aturan yang hanya terdapat proses fungsi implikasi, dan defuzzifikasi menggunakan metode rata - rata terpusat (weight average). Untuk proses pada metode Mamdani dan Sugeno memiliki empat tahap yang sama yaitu fuzzifikasi, pembentukan aturan, analisis aturan dengan fungsi implikasinya menggunakan fungsi $M I N$ dan juga terdapat proses komposisi aturan yang dapat menggunakan metode $M A X$, dan yang terakhir yaitu tahap defuzzifikasi. Untuk proses defuzzifikasi, pada metode Mamdani menggunakan metode centroid dan pada metode Tsukamoto dan Sugeno menggunakan metode rata - rata terpusat (weight average) (Setiadji, 2009: 206).

Perusahaan CV. Dewi Bulan berdiri mulai pada tahun 1991 hingga kini. Perusahaan ini bertempat di Jalan Seroya, Perumahan Hindia Indah Denpasar, Bali. Perusahaan CV. Dewi Bulan merupakan perusahaan yang bergerak dalam bidang produksi dupa lokal tradisional Bali. Oleh karena itu, CV. Dewi Bulan ini memproduksi berbagai macam produk dupa lokal, seperti dupa lokal jenis lidi, dupa lilin serta jenis dupa import. 
Himpunan logika fuzzy diperkenalkan oleh Lotfi A. Zadeh pada tahun 1965 sebagai cara matematis untuk merepresentasikan ketidakpastian linguistik (Kusumadewi dan Purnomo, 2010:1). Ada beberapa hal yang perlu diketahui dalam memahami metode fuzzy, yaitu:
a. Variabel fuzzy
Variabel fuzzy merupakan suatu lambang atau kata yang menunjuk kepada suatu yang tidak tertentu dalam sistem fuzzy.

b. Himpunan fuzzy

Himpunan fuzzy merupakan suatu kumpulan yang mewakili suatu kondisi atau keadaan tertentu dalam suatu variabel fuzzy.

c. Semesta pembicaraan

Semesta pembicaraan adalah keseluruhan nilai yang diperbolehkan untuk dioperasikan dalam suatu variabel fuzzy.

d. Domain

Domain himpunan fuzzy adalah keseluruhan nilai yang diijinkan dalam semesta pembicaraan dan boleh dioperasikan dalam suatu himpunan fuzzy.

Dalam sistem inferensi fuzzy terdapat beberapa metode, salah satunya metode Tsukamoto. Pada dasarnya, metode Tsukamoto mengaplikasikan penalaran pada setiap aturannya. Pada metode Tsukamoto, sistem terdiri atas beberapa aturan dimana setiap konsekuen pada aturan yang berbentuk $I F$... THEN ... harus direpresentasikan dengan suatu himpunan fuzzy dengan fungsi keanggotaan yang monoton (Kusumadewi dan Purnomo, 2010).

\section{Metode Mamdani}

Sistem inferensi fuzzy Metode Mamdani dikenal juga dengan nama metode Max-Min. Metode Mamdani bekerja berdasarkan aturanaturan linguistik. Metode ini diperkenalkan oleh Ebrahim H. Mamdani pada tahun 1975 (Kusumadewi dan Purnomo, 2010).

Metode Sugeno, penalarannya hampir sama dengan penalaran Mamdani, hanya saja output sistem tidak berupa himpunan fuzzy, melainkan berupa konstanta atau persamaan linear. Metode ini diperkenalkan oleh Takagi-Sugeno Kang pada tahun 1985 (Kusumadewi dan Purnomo, 2010).

Mean Absolute Percentage Error (MAPE) merupakan suatu ukuran akurasi penentuan nilai hasil dari metode hasil pengamatan yang digunakan. Caranya yaitu dengan menghitung selisih dari output produksi yang diperoleh dengan nilai data yang didapat, kemudian dibagi dengan banyaknya data. Hasilnya yang berbentuk perentase kemudian dimutlakkan. Perhitungan ini dilakukan pada setiap amatannya kemudian dirata-ratakan (Harun, 1999).

\section{METODE PENELITIAN}

Jenis data yang digunakan dalam penelitian ini adalah data primer (langsung) yang diperoleh dari pemilik CV. Dewi Bulan. Data tersebut adalah data produk dupa mulai dari awal bulan mei 2011 sampai akhir bulan april 2016. Data produk dupa ini meliputi permintaan, persediaan dan jumlah produksi dupa.

Identifikasi masalah pada penelitan ini adalah untuk menentukan jumlah produksi dupa pada CV. Dewi Bulan. Hal ini dikarenakan, selama ini perusahaan CV. Dewi Bulan belum dapat menentukan banyaknya dupa yang diproduksi secara berkala saat permintaan yang diminta maksimum dan memenuhi kapasitas produksi yang telah ditentukan.

Pada penelitian ini, metode analisis data yang digunakan adalah metode logika sistem inferensi fuzzy Tsukamoto, Mamdani dan Sugeno. Berikut ini langkah-langkah analisis data yang akan dilakukan, yaitu :

1. Menentukan range dan fungsi keanggotaan dari masing-masing atribut linguistik. range dari atribut linguistik variabel permintaan, persediaan dan produksi dijelaskan berdasarkan data yang telah didapat pada perusahaan CV.Dewi Bulan.

2. Penentuan fungsi pada konsekuen untuk masing-masing aturan implikasi pada setiap metode yang digunakan.

3. Membentuk aturan implikasi fuzzy dengan mengkombinasikan setiap atribut linguistik pada setiap variabel input. 
4. Melakukan defuzzifikasi dengan menghitung rata-rata terbobot dari semua aturan implikasi fuzzy.

5. Melakukan simulasi Fuzzy Inference System Tsukamoto, Mamdani dan Sugeno untuk menentukan ketepatan jumlah produksi dupa.

6. Menghitung nilai $M A P E$ untuk menentukan keakuratan dari Fuzzy Inference System yang digunakan.

\section{HASIL DAN PEMBAHASAN}

\section{Metode Tsukamoto}

Pada metode fuzzy Tsukamoto, terdapat tiga langkah untuk menentukan jumlah produksi berdasarkan variabel input yaitu permintaan dan persediaan. Empat langkah fuzzy Tsukamoto tersebut antaranya; fuzzifikasi, pembentukan aturan fuzzy, analisis logika fuzzy dan defuzzyfikasi. Berikut range dari data permintaan, persediaan, dan produksi dupa;

$\begin{array}{ll}\text { Permintaan }_{\text {RENDAH }} & =[13200,14266] \\ \text { Permintaan }_{\text {SEDANG }} & =[13724,14808] \\ \text { Permintaan }_{\text {TINGGI }} & =[14266,15450] \\ \text { Persediaan }_{\text {SEDIKIT }} & =[40,285] \\ \text { Persediaan }_{\text {SEDANG }} & =[167,404] \\ \text { Persediaan }_{\text {BANYAK }} & =[285,490] \\ \text { Produksi }_{\text {KECIL }} & =[13140,14265] \\ \text { Produksi }_{\text {SEDANG }} & =[13709,14820] \\ \text { Produksi }_{\text {BESAR }} & =[14265,15450]\end{array}$

Untuk langkah metode Tsukamoto, yaitu dijelaskan sebagai berikut;

1. Fuzzyfikasi

Variabel Permintaan dibagi 3 variabel linguistik yaitu RENDAH, SEDANG dan TINGGI. Himpunan fuzzy RENDAH terbagi menjadi 3 daerah yaitu;

Himpunan fuzzy Permintaan RENDAH;

$$
\mu_{\text {PITRENDAH }}[x]=\left\{\begin{array}{cc}
0, & x>14266 \\
\frac{14266-x}{1066}, & 13200 \leq x \leq 14266 \\
1, & x<13200
\end{array}\right.
$$

Himpunan fuzzy Permintaan SEDANG;

$$
\mu_{\text {PmtSEDANG }}[x]=\left\{\begin{array}{cc}
0, & x<13724 \text { dan } x>14808 \\
\frac{x-13724}{542}, & 13724 \leq x \leq 14266 \\
\frac{14808-x}{542}, & 14266<x \leq 14808
\end{array}\right.
$$

Himpunan fuzzy Permintaan TINGGI;

$$
\mu_{\text {PmtTINGGI }}[x]=\left\{\begin{array}{cc}
1, & x>15450 \\
\frac{x-14266}{1184}, & 14266 \leq x \leq 15450 \\
0, & x<14266
\end{array}\right.
$$

Variabel Persediaan dibagi 3 variabel linguistik yaitu SEDIKIT, SEDANG dan BANYAK.

Himpunan fuzzy Persediaan SEDIKIT;

$$
\mu_{\text {PSdSEDIKIT }}[y]=\left\{\begin{array}{cc}
1, & y<40 \\
\frac{285-y}{245}, & 40 \leq y \leq 285 \\
0, & y>285
\end{array}\right.
$$

Himpunan fuzzy Persediaan SEDANG;

$$
\mu_{\text {PSASEDANG }}[y]=\left\{\begin{array}{cc}
0, & y<167 \text { dan } y>404 \\
\frac{y-167}{118}, & 167 \leq y \leq 285 \\
\frac{406-y}{119}, & 285<y \leq 404
\end{array}\right.
$$

Himpunan fuzzy Persediaan BANYAK;

$$
\mu_{P S d B A N Y A K}[y]=\left\{\begin{array}{cc}
0, & y<285 \\
\frac{y-285}{205}, & 285 \leq x \leq 490 \\
1, & y>490
\end{array}\right.
$$

Variabel Produksi dibagi 3 variabel linguistik yaitu KECIL, SEDANG dan BESAR. Himpunan fuzzy Produksi KECIL;

$$
\mu_{\text {ProdKECIL }}[z]=\left\{\begin{array}{cc}
0, & z>14265 \\
\frac{14265-z}{1125}, & 13140 \leq z \leq 14265 \\
1, & z<13140
\end{array}\right.
$$

Himpunan fuzzy Produksi SEDANG;

$$
\mu_{\text {ProdSEDANG }}[z]=\left\{\begin{array}{cc}
0, & z<13709 \text { dan } z>14820 \\
\frac{z-13709}{556}, & 13709 \leq z \leq 14265 \\
\frac{14820-z}{555}, & 14265<z \leq 14820
\end{array}\right.
$$

Himpunan fuzzy Produksi BESAR

$$
\mu_{\text {ProdBESAR }}[z]=\left\{\begin{array}{cc}
0, & z<14265 \\
\frac{z-14265}{1185}, & 14265 \leq z \leq 15450 \\
1, & z>15450
\end{array}\right.
$$

2. Pembentukan aturan fuzzy

Pada pembentukan aturan, terdapat tiga variabel dengan range dari atribut linguistiknya dibagi menjadi tiga bagian sehingga dibuat $3^{3}$ 
aturan yaitu 27 aturan, yang merupakan semua kemungkinan aturan yang dapat terjadi.

3. Analisis logika fuzzy

Pada analisis logika fuzzy pada metode Tsukamoto, dilakukan proses fungsi implikasi dengan metode fungsi MIN. Sehingga didapatkan nilai $\alpha$-predikat dan $z$ pada masing masing aturannya.

\section{Defuzzifikasi}

Selanjutnya akan dilakukan perhitungan nilai z (output) berdasarkan aturan - aturan yang digunakan sehingga didapat:

$$
\begin{aligned}
& Z=\frac{\alpha_{\text {predikat }_{1}} * Z_{1}+\alpha_{\text {predikat }_{2}} * Z_{2}++\cdots+\alpha_{\text {predikat }_{9}} * Z_{27}}{\alpha_{\text {predikat }_{1}}+\alpha_{\text {predikat }_{2}}++\cdots+\alpha_{\text {predikat }_{27}}} \\
& Z=\frac{0,31 * 42429,96+0,45 * 42516,2+0,015 * 84496,48}{0,93+1,35+0,09} \\
& Z=14157,394=14158
\end{aligned}
$$

\section{Metode Mamdani}

Terdapat empat langkah yang harus dilakukan untuk menentukan jumlah produksi dengan metode Mamdani, yaitu:

\section{Fuzzifikasi}

Seperti yang telah dijelaskan sebelumnya terdapat 3 variabel pada penelitian ini, 2 diantarnya sebagai input yaitu variabel permintaan dan persediaan sedangkan satu sisanya merupakan variabel output yaitu variabel produksi.

\section{Pembentukan aturan fuzzy}

Aturan yang diterapkan pada metode Mamdani sebanyak 27 aturan.

3. Analisis logika fuzzy

Pada analisis logika fuzzy pada metode Mamdani, dilakukan proses fungsi implikasi dengan metode fungsi MIN. dan proses komposisi aturannya dengan menggunakan fungsiMAX.

\section{Defuzzyfikasi}

Metode penegasan/defuzzyfikasi yang akan digunakan adalah metode Centoid. Sehingga didapat gambar sebagai berikut;

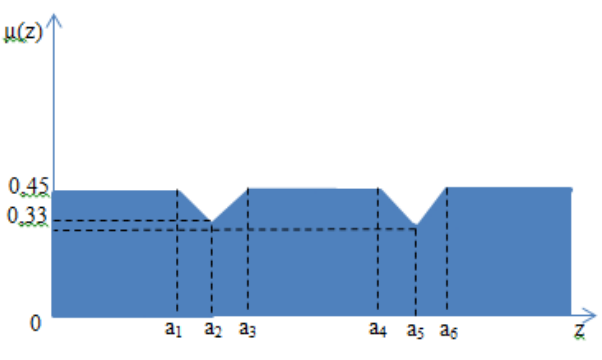

Gambar 1. Daerah hasil komposisi

Selanjutnya dihitung, fungsi keanggotaan untuk hasil komposisi diatas yaitu;

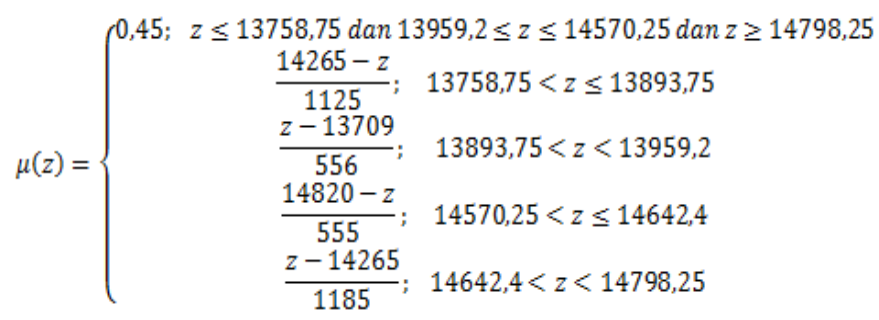

Selanjutnya, menghitung momen untuk setiap daerah yang dijelaskan sebagai berikut;.

$$
\begin{aligned}
& M 1=\int_{13140}^{13758,75}(0,45) z d z=0,\left.225 z^{2}\right|_{1370} ^{13758,75}=3744810,352 \\
& M 2=\int_{1375,75}^{13993,75}\left(\frac{14265-z}{1125}\right) z d z=1215244.917 \\
& M 3=\int_{13893,75}^{13959,2}\left(\frac{z-13709}{556}\right) z d z=375260.561 \\
& M 4=\int_{13959,2}^{14570,25}(0,45) z d z=0,\left.225 z^{2}\right|_{13959,2} ^{14570,25}=3922407.095
\end{aligned}
$$

$M 5=\int_{14570,25}^{14642,4}\left(\frac{14820-z}{555}\right) z d z=432668.781$

$M 6=\int_{14642,4}^{14798,25}\left(\frac{z-14265}{1185}\right) z d z=746035.319$

$M 7=\int_{14798,25}^{15450}(0,45) z d z=0,\left.225 z^{2}\right|_{14798,25} ^{15450}=4435716.811$

Kemudian hitung luas setiap daerah;

$$
\begin{aligned}
& \text { A1 }=0,45 *(13758,75-13140)=278,43 \\
& \text { A2 }=\frac{0,33+0,45}{2} *(13893,75-13758,75)=52,65 \\
& \text { A3 }=\frac{0,33+0,45}{2} *(13959,2-13893,75)=25,52 \\
& \text { A4 }=0,45 *(14570,25-13959,2)=274,97
\end{aligned}
$$




$$
\begin{aligned}
& \text { A5 }=\frac{0,32+0,45}{2} *(14642,4-14570,25)=27,78 \\
& \text { A6 }=\frac{0,32+0,45}{2} *(14798,25-14642,4)=60,01 \\
& \text { A7 }=0,45 *(15450-14798,25)=293,28
\end{aligned}
$$

Sehingga untuk menghitung titik pusatnya, berlaku $z=\frac{M 1+M 2+\cdots+M 7}{A 1+A 2+\cdots+A 7}$, didapat nilai $z$ yaitu; $z=14686,506=14687$

\section{Metode Sugeno}

1. Fuzzifikasi

Seperti yang telah dijelaskan sebelumnya terdapat 3 variabel pada penelitian ini, dua diantarnya sebagai input yaitu variabel permintaan dan persediaan dan satu variabel output yaitu produksi.

2. Pembentukan aturan fuzzy

Dari aturan-aturan yang terbentuk berdasarkan basis aturan pada inferensi fuzzy, maka aturan-aturan yang mungkin dan sesuai dengan basis pengetahuan sesuai dari perusahaan ada 9 aturan, yaitu:

[R1] IF Permintaan TURUN, dan Persediaan BANYAK, THEN (Z1) Produksi Dupa = Permintaan - Persediaan;

[R2] IF Permintaan TURUN, dan Persediaan SEDANG, THEN (Z2) Produksi Dupa = Permintaan - Persediaan;

[R3] IF Permintaan TURUN, dan Persediaan TURUN, THEN (Z3) Produksi Dupa = Permintaan;

[R4] IF Permintaan SEDANG, dan Persediaan BANYAK, THEN (Z4) Produksi Dupa = Permintaan;

[R5] IF Permintaan SEDANG, dan Persediaan SEDANG, THEN (Z5) Produksi Dupa = Permintaan;

[R6] IF Permintaan SEDANG, dan Persediaan SEDIKIT, THEN (Z6) Produksi Dupa = Permintaan - (1,2*Persediaan);

[R7] IF Permintaan BANYAK, dan Persediaan BANYAK, THEN (Z7) Produksi Dupa = Permintaan;

[R8] IF Permintaan BANYAK, dan Persediaan SEDANG, THEN (Z8) Produksi Dupa = Permintaan $-1,2 *$ Persediaan;
[R9] IF Permintaan BANYAK, dan Persediaan SEDIKIT, THEN (Z9) Produksi Dupa = Permintaan $-1,2 *$ Persediaan;

3. Analisis logika fuzzy

Aplikasi fungsi implikasi menggunakan fungsi $M I N$ pada tiap aturannya, dan digunakan fungsi MAX untuk melakukan komposisi antar semua aturan.

\section{Defuzzyfikasi}

Karena $\alpha$-predikat yang tidak nol hanya terdapat pada aturan R4, R5, R7 dan R8. Sehingga yang memenuhi fungsi $M A X$ adalah aturan R4, R5 dan R8, dengan menggunakan metode defuzzy weighted average, maka rata rata jumlah produksinya adalah;

$z=\frac{\alpha_{4} z_{4}+\alpha_{5} z_{5}+\alpha_{8} z_{8}}{\alpha_{4}+\alpha_{5}+\alpha_{8}}$

$z=\frac{0,31 * 14250+0,45 * 14250+0,015 * 13830}{0,31+0,45+0,015}$

$z=14241,87=14242$

\section{Hasil perbandingan fuzzy Tsukamoto, Mamdani dan Sugeno}

Dari hasil uji data, dimana bila jumlah permintaan $=14250$ dan persediaan $=350$. Didapat bahwa jumlah produksi pada periode Mei 2011 untuk metode Tsukamoto $=14158$, untuk jumlah produksi pada metode Mamdani $=$ 14687, dan untuk jumlah produksi pada metode Sugeno $=14242$. Dengan diketahui produksi pada periode Mei 2011 sebesar 14340, maka didapat jumlah produksi dengan metode Sugeno pada Mei 2011 yaitu sebesar 14242 adalah metode yang paling medekati dari hasil jumlah produksi dupa pada periode Mei 2011, Berikut tabel hasil produksi dupa per batang beserta hasil produksi dupa per batang dengan metode Tsukamoto, Mamdani dan Sugeno; 
Tabel A. Hasil Perbandingan Metode Tsukamoto, Mamdani dan Sugeno

\begin{tabular}{|c|c|c|c|c|}
\hline Periode & $\begin{array}{c}\text { Data } \\
\text { Produksi }\end{array}$ & $\begin{array}{c}\text { Produksi } \\
\text { Tsukamoto }\end{array}$ & $\begin{array}{l}\text { Produksi } \\
\text { Mamdani }\end{array}$ & $\begin{array}{c}\text { Produksi } \\
\text { Sugeno }\end{array}$ \\
\hline Mei 2011 & 14340 & 13981 & 14687 & 14242 \\
\hline Juni 2011 & 14200 & 13814 & 14505 & 13826 \\
\hline July 2011 & 14710 & 14131 & 14862 & 14332 \\
\hline $\begin{array}{l}\text { Agustus } \\
2011\end{array}$ & 14290 & 13945 & 14568 & 13840 \\
\hline $\begin{array}{l}\text { September } \\
2011\end{array}$ & 15450 & 14579 & 15278 & 15047 \\
\hline $\begin{array}{l}\text { Oktober } \\
2011\end{array}$ & 14450 & 14015 & 14751 & 14389 \\
\hline $\begin{array}{l}\text { November } \\
2011\end{array}$ & 14650 & 14083 & 14797 & 14223 \\
\hline $\begin{array}{l}\text { Desember } \\
2011\end{array}$ & 14510 & 14013 & 14738 & 14193 \\
\hline Januari 2012 & 13310 & 13325 & 13505 & 13335 \\
\hline $\begin{array}{l}\text { Februari } \\
2012\end{array}$ & 13880 & 13650 & 14172 & 13691 \\
\hline Maret 2012 & 13940 & 13714 & 14240 & 13756 \\
\hline April 2012 & 14120 & 13792 & 14416 & 13845 \\
\hline Mei 2012 & 13960 & 13664 & 14256 & 13698 \\
\hline Juni 2012 & 13310 & 13350 & 13352 & 13372 \\
\hline July 2012 & 14570 & 14125 & 14864 & 14220 \\
\hline $\begin{array}{l}\text { Agustus } \\
2012\end{array}$ & 14250 & 13898 & 14571 & 13958 \\
\hline $\begin{array}{l}\text { September } \\
2012\end{array}$ & 14280 & 13911 & 14515 & 13911 \\
\hline $\begin{array}{l}\text { Oktober } \\
2012\end{array}$ & 14200 & 13866 & 14442 & 13925 \\
\hline $\begin{array}{l}\text { November } \\
2012\end{array}$ & 14670 & 14272 & 14810 & 14312 \\
\hline $\begin{array}{l}\text { Desember } \\
2012\end{array}$ & 15250 & 14750 & 14477 & 14923 \\
\hline Januari 2013 & 13410 & 13441 & 13539 & 13460 \\
\hline $\begin{array}{l}\text { Februari } \\
2013 \\
\end{array}$ & 14320 & 13943 & 14511 & 14101 \\
\hline Maret 2013 & 14300 & 13956 & 14536 & 14087 \\
\hline April 2013 & 13140 & 13175 & 13365 & 13195 \\
\hline Mei 2013 & 13480 & 13427 & 13672 & 13527 \\
\hline Juni 2013 & 13740 & 13647 & 13921 & 13776 \\
\hline July 2013 & 13620 & 13540 & 13934 & 13660 \\
\hline $\begin{array}{l}\text { Agustus } \\
2013 \\
\end{array}$ & 13960 & 13762 & 14275 & 13812 \\
\hline $\begin{array}{l}\text { September } \\
2013\end{array}$ & 13540 & 13425 & 13592 & 13414 \\
\hline $\begin{array}{l}\text { Oktober } \\
2013 \\
\end{array}$ & 13870 & 13663 & 14195 & 13703 \\
\hline $\begin{array}{l}\text { November } \\
2013\end{array}$ & 14250 & 13928 & 14581 & 14028 \\
\hline $\begin{array}{l}\text { Desember } \\
2013\end{array}$ & 14320 & 14012 & 14576 & 14102 \\
\hline Januari 2014 & 14920 & 14160 & 15056 & 14690 \\
\hline
\end{tabular}

\begin{tabular}{|c|c|c|c|c|}
\hline $\begin{array}{l}\text { Februari } \\
2014\end{array}$ & 14200 & 14006 & 14484 & 14124 \\
\hline Maret 2014 & 15180 & 14482 & 15152 & 14891 \\
\hline April 2014 & 14800 & 14148 & 14983 & 14645 \\
\hline Mei 2014 & 14400 & 14047 & 14727 & 14234 \\
\hline Juni 2014 & 14770 & 14133 & 14919 & 14572 \\
\hline July 2014 & 14710 & 14125 & 14928 & 14585 \\
\hline $\begin{array}{l}\text { Agustus } \\
2014\end{array}$ & 14190 & 13882 & 14488 & 13922 \\
\hline $\begin{array}{l}\text { September } \\
2014\end{array}$ & 15350 & 14574 & 15315 & 15197 \\
\hline $\begin{array}{l}\text { Oktober } \\
2014\end{array}$ & 14460 & 14062 & 14834 & 14315 \\
\hline $\begin{array}{l}\text { November } \\
2014\end{array}$ & 14950 & 14257 & 15112 & 14833 \\
\hline $\begin{array}{l}\text { Desember } \\
2014\end{array}$ & 14810 & 14197 & 15080 & 14695 \\
\hline Januari 2015 & 13610 & 13320 & 13814 & 13541 \\
\hline $\begin{array}{l}\text { Februari } \\
2015\end{array}$ & 14080 & 13881 & 14346 & 13925 \\
\hline Maret 2015 & 14040 & 13865 & 14291 & 13906 \\
\hline April 2015 & 14240 & 14025 & 14526 & 14104 \\
\hline Mei 2015 & 14060 & 13873 & 14355 & 13913 \\
\hline Juni 2015 & 13610 & 13320 & 13861 & 13489 \\
\hline July 2015 & 14670 & 14085 & 14871 & 14525 \\
\hline $\begin{array}{l}\text { Agustus } \\
2015\end{array}$ & 14250 & 14028 & 14416 & 14162 \\
\hline $\begin{array}{l}\text { September } \\
2015\end{array}$ & 14280 & 13642 & 14403 & 14118 \\
\hline $\begin{array}{l}\text { Oktober } \\
2015\end{array}$ & 14200 & 14013 & 14387 & 14014 \\
\hline $\begin{array}{l}\text { November } \\
2015\end{array}$ & 14970 & 14247 & 15095 & 14767 \\
\hline $\begin{array}{l}\text { Desember } \\
2015\end{array}$ & 15250 & 14640 & 15273 & 15013 \\
\hline Januari 2016 & 13410 & 13206 & 13446 & 13326 \\
\hline $\begin{array}{l}\text { Februari } \\
2016\end{array}$ & 14320 & 14092 & 14579 & 14231 \\
\hline Maret 2016 & 14700 & 14146 & 14940 & 14496 \\
\hline April 2016 & 13140 & 13177 & 13256 & 13149 \\
\hline \multicolumn{2}{|c|}{ MAPE } & $2,525 \%$ & $1,557 \%$ & $1,314 \%$ \\
\hline
\end{tabular}

\section{KESIMPULAN DAN SARAN}

Berdasarkan pembahasan mengenai perbandingan metode Tsukamoto, metode Mamdani dan Metode Sugeno untuk menentukan jumlah produksi dupa berdasarkan data jumlah permintaan dan jumlah persediaan maka dapat disimpulkan bahwa nilai MAPE pada metode Tsukamoto sebesar 2,525\%, metode Mamdani sebesar $1,557 \%$, dan metode 
Sugeno sebesar $1,314 \%$, untuk metode Sugeno memiliki nilai error terkecil pada jumlah produksi dupa pada kasus di CV. Dewi Bulan, nilai error didapat dari perbandingan data hasil produksi setiap metode yang digunakan dengan data produksi yang didapat dari CV. Dewi Bulan secara langsung. Sehingga berdasarkan hasil yang didapat metode Sugeno yang paling baik untuk digunakan dibandingkan dengan metode Tsukamoto dan metode Mamdani pada studi kasus produksi dupa CV. Dewi Bulan.

Pada penelitian ini, terdapat 2 variabel input, yaitu permintaan dupa dan persediaan dupa, serta 1 variabel output, yaitu jumlah dupa yang akan diproduksi. Untuk penelitian penelitian selanjutnya disarankan agar jumlah variabel input yang dapat digunakan lebih dari 2.

\section{DAFTAR PUSTAKA}

Susilo, Frans SJ. 2006. "Himpunan dan Logika Kabur serta Aplikasinya". Yogyakarta: Graha Ilmu.

Harun, S. 1999. Forecasting and Simulation of Net Inflows for Reservoir Operation and Management. Malaysia : Thesis. Universiti Teknologi Malaysia.

Kusumadewi, Sri. Purnomo Hari. 2010.Aplikasi Logika Fuzzy (Fuzzy Inference System). Yogyakarta: Graha Ilmu.

Setiadji. 2009. Himpunan dan Logika Samar serta Aplikasinya. Yogyakarta: Graha Ilmu. 